\title{
WP 16-05
}

\author{
Barbara Annicchiarico \\ University of Rome Tor Vergata, Italy
}

Alessandra Pelloni

University of Rome Tor Vergata, Italy

The Rimini Centre for Economic Analysis, Italy

Fabrizio Valenti

University of Rome Tor Vergata, Italy

\section{VOLATILITY AND GROWTH WITH RECURSIVE PREFERENCES}

Copyright belongs to the author. Small sections of the text, not exceeding three paragraphs, can be used provided proper acknowledgement is given.

The Rimini Centre for Economic Analysis (RCEA) was established in March 2007. RCEA is a private, nonprofit organization dedicated to independent research in Applied and Theoretical Economics and related fields. RCEA organizes seminars and workshops, sponsors a general interest journal The Review of Economic Analysis, and organizes a biennial conference: The Rimini Conference in Economics and Finance (RCEF). The RCEA has a Canadian branch: The Rimini Centre for Economic Analysis in Canada (RCEA-Canada). Scientific work contributed by the RCEA Scholars is published in the RCEA Working Papers and Professional Report series.

The views expressed in this paper are those of the authors. No responsibility for them should be attributed to the Rimini Centre for Economic Analysis. 


\title{
Volatility and Growth with Recursive Preferences
}

\author{
Barbara Annicchiarico* Alessandra Pelloni ${ }^{\dagger} \quad$ Fabrizio Valenti $^{\ddagger}$
}

April 2016

\begin{abstract}
This paper studies the relationship between volatility and long-run growth in a complete market economy with human capital accumulation and Epstein-Zin preferences. There is both crosscountry and time-series evidence that volatility is associated with lower growth. Matching this evidence has proved a challenge for growth models with no market failures as they tend to predict the opposite for values of risk aversion higher than unity. However in our model, risk aversion and intertemporal elasticity of substitution are allowed to move independently of each other, and when both are relatively high or relatively low, the relationship between volatility and growth is negative. Indeed this is the case for parametrizations of preferences in line with the literature.
\end{abstract}

JEL classification: D92; E22; E32; O49.

Keywords: Growth and Uncertainty; Epstein-Zin Preferences; Intertemporal Elasticity of Substitution; Risk Aversion

* Corresponding Author: Dipartimento di Economia e Finanza, Università degli studi di Roma Tor Vergata, Via Columbia 2, 00133, Roma, Italy; e-mail: barbara.annicchiarico@uniroma2.it.

${ }^{\dagger}$ Dipartimento di Economia e Finanza, Università degli studi di Roma Tor Vergata, Via Columbia 2, 00133, Roma, Italy; e-mail: alessandra.pelloni@uniroma2.it

${ }^{\ddagger}$ Dipartimento di Economia e Finanza, Università degli studi di Roma Tor Vergata, Via Columbia 2, 00133, Roma, Italy; e-mail: valenti@economia.uniroma2.it 


\section{Introduction}

Ramey and Ramey (1995) present evidence that more volatile economies tend to grow less. This conclusion has been confirmed by other empirical investigations. ${ }^{1}$ The negative relationship between the frequency and amplitude of the business cycle and long-run growth also exists in the U.S. time series. This is shown in Figure 1. The top graph shows average GDP growth and the variance of GDP growth, while in the bottom one we have plotted average total factor productivity (TFP) growth and its variance. The time series plotted are obtained computing averages and variances over five-year rolling windows. Overall, in the charts the relationship between volatility and growth is clearly negative. However, in complete-markets economies, for plausible degrees of risk aversion, volatility causes an increase in precautionary investments in physical or human capital, implying an increase in long-run growth (see Canton 2002, De Hek 1999 and Jones et al. 2005). ${ }^{2}$

Various explanations have been proposed for the negative association between mean growth and its standard deviation that the data seem to suggest: credit constraints (Aghion and Banerjee 2005 and Aghion et al. 2010) wage and price setting (Annicchiarico and Pelloni 2014, Blackburn and Pelloni 2004 and Blackburn and Pelloni 2005) and countercyclical mark-ups leading to extrinsic uncertainty (Wang and Wen 2011).

Our work shows that a model in which unbounded growth is driven by human and physical capital accumulations is capable of delivering a negative relationship between volatility and growth just by adopting Kreps and Porteus (1978) preferences (in their Epstein and Zin 1989 specification), without having to resort to any source of inefficiency. This striking result exploits the main characteristic of Epstein-Zin (EZ) preferences, i.e. that they allow to treat risk aversion and intertemporal elasticity of substitution separately. ${ }^{3}$ We will see, in fact, that the relationship between volatility and growth crucially depends on the interplay between these two primitives. In particular, we will demonstrate that when both are relatively high or relatively low, the relationship between uncertainty and growth is negative. A negative sign is easy to obtain for parameters' values in line with those used in the literature (e.g. Kung and Schmid 2015, and Van Binsbergen et al. 2012). So we put EZ preferences at work beyond their traditional use as an instrument to overcome the equity premium puzzle in

\footnotetext{
${ }^{1}$ See, e.g., Aghion et al. (2010), Campos and Karanasos (2008), Grier and Perry (2000), Grier et al. (2004), Loayza and Hnatkovska (2004), Martin and Rogers (2000), Mobarak (2005) and Rafferty (2005), among others.

${ }^{2}$ This is also the case in the presence of idiosyncratic uninsurable risk as shown by Krebs (2003).

${ }^{3} \mathrm{~A}$ problem with Von-Neumann Morgenstern preferences is that constraining risk aversion and intertemporal elasticity of substitution to be one the inverse of the other imply that individuals are indifferent to the timing of resolution of uncertainty.
} 
asset pricing theory. ${ }^{4}$

Epaulard and Pommeret (2003), like us, analyze the effect of volatility on growth in a model with EZ preferences. Using a simple $A K$ model they show that the sign of the effect of uncertainty on growth is exclusively governed by intertemporal elasticity of substitution, while risk aversion only influences the size of such effect. Our work, instead, shows that the sign of the relationship between volatility and growth crucially depends on both risk aversion and intertemporal elasticity of substitution. We demonstrate that this substantial difference in results is due to the assumption in their paper that only capital and not labour is needed for producing, so that the choice of how much to work is not part of the optimization problem of agents. In other words we show that labour supply plays an important role in determining how uncertainty influences growth and how risk aversion and intertemporal elasticity of substitution affect that influence.

A paper related to our work is Saltari and Ticchi (2007): it shows that with EZ preferences the relationship between uncertainty and investment is negative when either the intertemporal elasticity of substitution is greater than one and risk aversion is above a certain threshold or the elasticity of substitution is lower than one and risk aversion is below a certain threshold. However in the model the result is based on the assumption of constant real wages and the specification of preferences is inconsistent with long-run growth (see Trabandt and Uhlig 2011). ${ }^{5}$

The attractiveness of EZ preferences is somewhat counterbalanced by the relative difficulty of working with them. We follow the solution proposed by Van Binsbergen et al. (2012) that suggests adopting a method relying on perturbations, instead of value function iteration (see Croce et al. 2006) or projection methods (see Campanale et al. 2010).

Our paper is structured as follows: in Section 2 we introduce and solve the model, in Section 3 we present and discuss our results and in Section 4 we draw our conclusions.

\footnotetext{
${ }^{4}$ Epstein-Zin preferences have mostly been used to explain asset markets phenomena: a fundamental paper in this strain of research is Bansal and Yaron (2004) that shows that EZ preferences, when consumption and dividend growth rates contain a small long-run predictable component and a fluctuating one, can justify the equity premium, the risk-free rate and the volatility of the market return, risk free rate and the price-dividend ratio observed in the data.

${ }^{5}$ Femminis (2008) extends Saltari and Ticchi (2007) showing that it is possible to find an analytical solution to a general equilibrium model with EZ preferences even when capital depreciation is different from one.
} 


\section{The Model}

In this Section we introduce a general endogenous growth model with recursive preferences. The economy is characterized by three production factors: physical capital, human capital, and labour. The two types of capital accumulate according to the following functions:

$$
\begin{aligned}
& K_{t+1}=\left(1-\delta_{k}\right) K_{t}+I_{k, t}, \\
& H_{t+1}=\left(1-\delta_{h}\right) H_{t}+I_{h, t},
\end{aligned}
$$

where $H$ is human capital, $K$ is physical capital, $I_{k}\left(I_{h}\right)$ is investment in physical (human) capital and the parameters $\delta_{k}$ and $\delta_{h}$ measure the rate of capital depreciation. Throughout our work, we assume that physical capital depreciates at the same rate of human capital $\left(\delta_{h}=\delta_{k}\right)$. This assumption greatly simplifies computation and relaxing it does not change the qualitative results of the model. The representative firm has access to a standard Cobb-Douglas production function

$$
Y_{t}=A s_{t} K_{t}^{\alpha}\left(n_{t} H_{t}\right)^{1-\alpha},
$$

where $\alpha$ is the capital share, $A$ is a technological constant and $s_{t}$ introduces innovation in the model. In particular the structure of $s_{t}$ is

$$
\begin{aligned}
s_{t} & =\exp \left(\zeta_{t}-\frac{\sigma^{2}}{2\left(1-\varphi^{2}\right)}\right), \\
\zeta_{t} & =\varphi \zeta_{t-1}+\varepsilon_{t},
\end{aligned}
$$

where $\varepsilon \sim N\left(0, \sigma^{2}\right)$ and $0<\varphi<1$. This parametrization implies that changes in $\sigma^{2}$ do not affect the expected value of $s_{t}$, since, for every $x \sim N\left(\mu, \sigma^{2}\right), E\left(e^{x}\right)=e^{\mu+\frac{1}{2} \sigma^{2}}$.

The main characterizing feature of the model is that all households share the following KrepsPorteus (KP) preferences in their EZ specification:

$$
U_{t}=\left[(1-\beta)\left(C_{t}\left(1-\chi n_{t}\right)^{1-\omega}\right)^{1-\rho}+\beta\left[E_{t}\left(U_{t+1}^{1-\gamma}\right)\right]^{\frac{1-\rho}{1-\gamma}}\right]^{\frac{1}{1-\rho}},
$$

where $C$ is consumption, $\beta$ is the discount factor and $\chi$ is a scaling parameter, $\rho$ is the inverse of intertemporal elasticity of substitution, $\psi$, (i.e. $\rho=\psi^{-1}$ ), and $\gamma$ is risk aversion. The leisure- 
share parameter $\omega$ is important in determining labour-consumption choices of the individual and is constrained to be between 0 and 1 in order to ensure the concavity of the utility function and make sure that the Frisch elasticity of labour supply always assumes positive values. EZ preferences are fundamentally different from other non-recursive specifications in that they allow to disentangle the parameter measuring intertemporal elasticity of substitution from the one measuring risk aversion. Standard Von-Neumann-Morgensten preferences constrain risk aversion to be the inverse of intertemporal elasticity of substitution (in our context it would mean $\gamma=\rho$ ), while, with EZ preferences, these two parameters are allowed to freely assume any positive value.

Employing EZ preferences, thus, presents clear advantages, that, however, come at a cost: Epstein-Zin preferences are complex to handle and in most cases it is impossible to obtain closed form solutions, forcing those who want to employ them to resort to numerical methods. Moreover, in models that employ Epstein-Zin preferences, the value function itself is part of the first order conditions. Considering this fact and given the preferences described in (6), numerical simulations can be computationally complicated to handle when using extreme values of intertemporal elasticity of substitution or risk aversion. We can rewrite the problem in terms of the value function:

$$
V_{t}=\max _{n_{t}, K_{t+1}, H_{t+1}} U_{t}
$$

subject to the following resource constraint

$$
C_{t}+I_{k, t}+I_{h, t}=Y_{t}
$$

given (3), (4) and (5). The first-order conditions are then found to be

$$
\begin{gathered}
\frac{C_{t}}{1-\chi n_{t}}=\frac{1-\alpha}{\chi(1-\omega)} A s_{t}\left(\frac{K_{t}}{n_{t}}\right)^{\alpha} H_{t}^{1-\alpha} \\
1=E_{t}\left[M_{t+1}\left(1-\delta+\alpha A s_{t+1}\left(\frac{n_{t+1} H_{t+1}}{K_{t+1}}\right)^{1-\alpha}\right)\right], \\
1=E_{t}\left[M_{t+1}\left(1-\delta+(1-\alpha) A s_{t+1}\left(\frac{H_{t+1}}{K_{t+1}}\right)^{-\alpha} n_{t+1}^{1-\alpha}\right)\right],
\end{gathered}
$$




$$
\begin{gathered}
Y_{t}=C_{t}+K_{t+1}+H_{t+1}-(1-\delta)\left(K_{t}+H_{t}\right), \\
V_{t}=\left[(1-\beta)\left(C_{t}\left(1-\chi n_{t}\right)^{1-\omega}\right)^{1-\rho}+\beta\left[E_{t}\left(V_{t+1}^{1-\gamma}\right)\right]^{\frac{1-\rho}{1-\gamma}}\right]^{\frac{1}{1-\rho}},
\end{gathered}
$$

where $M_{t+1} \equiv \frac{\partial V_{t}}{\partial C_{t+1}} / \frac{\partial V_{t}}{\partial C_{t}}$, the pricing kernel in our economy, is given by

$$
M_{t+1}=\beta\left(\frac{\left[E_{t}\left(V_{t+1}^{1-\gamma}\right)\right]^{\frac{1}{1-\gamma}}}{V_{t+1}}\right)^{\gamma-\rho}\left(\frac{C_{t+1}\left(1-\chi n_{t+1}\right)^{1-\omega}}{C_{t}\left(1-\chi n_{t}\right)^{1-\omega}}\right)^{1-\rho} \frac{C_{t}}{C_{t+1}} .
$$

Using the convention $\operatorname{var}_{t}=\frac{V A R_{t}}{K_{t}}, g_{t+1}=\frac{K_{t+1}}{K_{t}}$, and $h_{t+1}=\frac{H_{t+1}}{K_{t}}$, we obtain the following stationary representation of the first-order conditions:

$$
\begin{gathered}
\frac{c_{t}}{1-\chi n_{t}}=\frac{1-\alpha}{\chi(1-\omega)} A s_{t} n_{t}^{-\alpha}\left(\frac{h_{t}}{g_{t}}\right)^{1-\alpha}, \\
1=E_{t}\left[M_{t+1}\left(1-\delta+\alpha A s_{t+1}\left(\frac{n_{t+1} h_{t+1}}{g_{t+1}}\right)^{1-\alpha}\right)\right] \\
1=E_{t}\left[M_{t+1}\left(1-\delta+(1-\alpha) A s_{t+1}\left(\frac{h_{t+1}}{g_{t+1}}\right)^{-\alpha} n_{t+1}^{1-\alpha}\right)\right] \\
c_{t}+g_{t+1}+h_{t+1}-(1-\delta)\left(1+\frac{h_{t}}{g_{t}}\right)-A s_{t}\left(\frac{n_{t} h_{t}}{g_{t}}\right)^{1-\alpha}=0, \\
V_{t}=\left[(1-\beta)\left(c_{t}\left(1-\chi n_{t}\right)^{1-\omega}\right)^{1-\rho}+\beta g_{t+1}^{1-\rho}\left(E_{t} V_{t+1}^{1-\gamma}\right)^{\frac{1-\rho}{1-\gamma}}\right]^{\frac{1}{1-\rho}}
\end{gathered}
$$

where $M_{t+1}$, the stochastic discount factor expressed in terms of stationary variables is

$$
M_{t+1}=\beta\left(\frac{\left[E_{t}\left(V_{t+1}^{1-\gamma}\right)\right]^{\frac{1}{1-\gamma}}}{V_{t+1}}\right)^{\gamma-\rho}\left(\frac{c_{t+1}\left(1-\chi n_{t+1}\right)^{1-\omega}}{c_{t}\left(1-\chi n_{t}\right)^{1-\omega}}\right)^{1-\rho} g_{t+1}^{-\rho} \frac{c_{t}}{c_{t+1}}
$$

The passages to obtain this representation are fairly straightforward, however, it is worth noting that in order to obtain equation (19) we have exploited the fact that the utility function is homothetic 
and, thus, homogeneous of degree 1. Notice that with this transformation the real discount factor now is $\beta g_{t+1}^{1-\rho}$. This discount factor depends positively on $\psi$, that is the intertemporal elasticity of substitution (recall that $\rho=\psi^{-1}$ ). Clearly, a higher $\psi$ implies more patient consumers that are more willing to delay consumption towards the future, when productivity will be higher.

In our simulations we will examine how the relationship between volatility and growth is influenced by risk aversion and intertemporal elasticity of substitution. However, given the employed preferences representation, we have to deal with the cases in which $\psi=1$ and $\gamma=1$ separately. These two special cases are described in the Appendix. It is also worth noting that there is a third special case, that is when $\gamma=\rho$ or, in other words, when risk aversion is equal to the inverse of intertemporal elasticity of substitution. In this latter case the utility function reduces to the standard Von-Neumann Morgenstern case.

\section{Simulations and Results}

As we mentioned before, the main disadvantage of employing EZ preferences is that, apart from a few special cases, it is often impossible to find closed form solutions. Unfortunately, the model in analysis is not one of these few exceptions, therefore, we have to resort to numerical simulations to compute the optimal decision rules. In particular, we follow the solution proposed by Van Binsbergen et al. (2012) that suggests, in order to tackle this kind of situations, to employ a perturbation method, instead of the value function iteration (Croce et al. 2006) or projections methods (Campanale et al. 2010). In particular, we will use a second - order perturbation method. This kind of approach, introduced by Judd and Guu (1997) and further developed by Schmitt-Grohé and Uribe (2004), is widely used in today's macroeconomic literature, also thanks to the ease with which it can now be implemented with off-the-shelf software. Given the optimal decision rules, we then draw a realization of $\left\{\varepsilon_{t}\right\}$ of size $1,000,000$ and compute the first moments using this realization.

\subsection{Calibration}

In order to compute the desired simulations, we first need to calibrate the model. We set the individual discount rate, $\beta$, equal to 0.95 , meaning that the length of a period is equal to one year. We set the capital share, $\alpha$, to 0.36 and the common depreciation rate of physical and human capital to $\delta=0.075$, as suggested by Jones et al. (2005). This is an intermediate value, greater than those 
estimated for the depreciation of human capital (usually between 1 and 4\%), but smaller than that of physical capital. We assume the standard deviation of the shock to be equal to $\sigma=0.011$ and its persistence to be equal to $\varphi=0.95$. For our benchmark simulation we will fix the parameter measuring risk aversion, $\gamma$, to 10 . This is a rather standard value in the literature dealing with EZ preferences, even if it is much greater than the value usually employed with standard Von-Neumann Morgenstern preferences. As far as it concerns the elasticity of intertemporal substitution, we will set it equal to 1.73 as estimated by Van Binsbergen et al. (2012). Moreover, notice that individuals in this context have a preference for early resolution of uncertainty, since $\gamma>\psi^{-1}$. We still have three "free" parameters, namely $\chi, \omega$, and $A$. Notice that in the general model the Frisch elasticity (for detailed passages, see the Appendix) is equal to:

$$
\text { Frisch }=\frac{1}{\chi} \frac{\rho}{\rho-(1-\omega)(1-\rho)} \frac{1-\chi n_{t}}{n_{t}} .
$$

This puts some restrictions on the possible values of $\omega$. In particular, in order to have a positive Frisch elasticity if $\rho>1$ this is always true, since $\omega>0$, however, if $\rho<1$ we need to have $1-\omega<\frac{\rho}{1-\rho}$. Moreover we also need to have that $\chi n<1$. In our benchmark simulations, we want to achieve a steady state growth rate equal to $2 \%$, a labour supply close to 0.17 (as estimated by Jones et al., 1993), and a Frisch elasticity of around 0.5. In order to match these desired values, starting from the steady state of the model, we set $A$ equal to $0.84, \omega$ equal to 0.0025 , and $\chi$ equal to 3.92 . The benchmark calibration is summarised in Table 1.

\subsection{Results}

For our benchmark simulation we fix risk aversion, $\gamma$, equal to 10, intertemporal elasticity of substitution, $\psi$, equal to 1.73 (following estimations by Van Binsbergen et al. 2012) and we try to match a steady state growth rate of $2 \%$ and a steady state labour supply of around 0.17 . Keeping our calibration constant we change $\gamma$ and $\psi$ and study how the relationship between volatility and growth is affected. Studying this relationship is straightforward: all we have to do is to compare the steady state value of the growth rate of output with its simulated first moment, $E\left(g^{y}\right)$. If the latter is greater than the former, volatility has a positive effect on output growth, while, when the contrary is true, uncertainty has a negative effect on long term growth. In our benchmark simulation we observe that the expected growth rate of output is $1.715 \%$, a remarkable result given 
that traditional expected utility models, when not accounting for nominal rigidities, show a positive relationship between volatility and growth.

To better understand the interplay between the degree of risk aversion and the intertemporal elasticity of substitution we now conduct some sensitivity analysis. Our first exercise consists in making $\gamma$ take different values (ranging from 0.5 and 20), while keeping risk aversion constant. The results of these simulations are presented in Table 2, where we report the expected growth rate of output, $E\left(g^{y}\right)$, along with expected level of labour inputs, $E(n)$, for different parametrizations. Notice that the steady state of our model only depends on intertemporal elasticity of substitution, thus, since in these first simulations we are only changing risk aversion, the steady state values of growth and labour supply remain the same along with all the other parameters of the model. Given the results displayed in Table 2, first of all, it is worth underlying that in this first set of simulations individuals always have a preference for early resolution of uncertainty $\left(\gamma>\psi^{-1}\right)$, but for simulation 1 (where $\gamma<\psi^{-1}$ ). Moreover, notice that the relationship between volatility and growth is not always negative. In particular, we notice that there must be a threshold value of risk aversion (between 2 and 4) after which the relationship between volatility and growth stops being positive and becomes negative.

Following Saltari and Ticchi (2007) we can explain the results we obtained by pinning down four different effects influencing the relationship between volatility and growth: the risk aversion effect, the labour flexibility effect, the income effect, and the substitution effect. These effects work in pairs: the labour flexibility and the risk aversion effects going against each other, and the income effect and the substitution effect working in opposite directions. Starting from the labour flexibility and the risk aversion effect, we notice that the former follows the fact the consumer-producer, after observing the realization of the shock, can substitute labour for capital. This, in general, means that the labour flexibility effect has a positive effect on the certainty equivalent of returns to investment. On the other hand, the risk aversion effect implies that uncertainty exerts a negative effect on the expected utility of future resources. If risk aversion is small enough, the labour flexibility effect is stronger than the risk aversion effect, while the opposite is true with high risk aversion. In particular, as long as the labour flexibility effect prevails (and this is the case for simulations 1-4) we have that volatility increases the certainty equivalent of returns to investment, so that intuitively the individual is richer. Since in Table 2 the intertemporal elasticity of substitution, $\psi$, is larger than one, the substitution effect prevails inducing the consumer to invest more and consume less. 
As a result, the final effect of uncertainty on growth is positive. By contrast, for higher values of the risk aversion, an increase in uncertainty gives rise to a reduction of the certainty equivalent of the return to capital. In these circumstances the substitution effect will push individuals to invest less because capital is less productive, that is why the final effect of uncertainty on growth is negative.

We now replicate the same experiment by keeping the intertemporal elasticity of substitution fixed $\psi$ at 0.5 . The parameters $A, \omega$ and $\chi$ are adjusted so as to keep the steady state growth rate equal to $2 \%$, the labour supply to 0.17 and the Frisch elasticity to $0.5{ }^{6}$ The results of these simulations are presented in Table 3. Under this new calibration we have that the labour flexibility effect prevails over the risk aversion effect in the first two simulations, implying a higher value of the certainty equivalent of the return to capital in the presence of uncertainty. Since the intertemporal elasticity of substitution is less than one, the income effect dominates the substitution effect. As a result, individuals tend to accumulate less capital and growth will be slightly lower on average. For a higher degree of risk aversion, instead, the certainty equivalent of the return to capital decreases with uncertainty. This effect coupled with dominance of the income effect over the substitution effect implies that agents invest more and consume less, so producing a positive effect of uncertainty on growth.

To further shed light on the role played by the interaction between intertemporal elasticity of substitution and risk aversion in determining the sign of the relationship between volatility and growth, in our next exercise we keep risk aversion fixed and we make intertemporal elasticity of substitution change between 0.2 and 2. Table 4 reports the results of this exercise when risk aversion is equal to 10 . In this case we keep the parameters $A, \omega$ and $\chi$ fixed and let the steady state values for growth and labour, along with the Frisch elasticity, to change accordingly to the different values of the intertemporal elasticity of substitution. By comparing the expected growth rate of output with its steady state counterpart, $g^{y}$, we notice that the relationship between volatility and growth is positive up until a certain value of the intertemporal elasticity of substitution (close to 1) and then becomes negative.

The results obtained confirm the intuition of Jones et al. (2005), that the parameters governing the curvature of the utility function (in this context risk aversion and intertemporal elasticity of

\footnotetext{
${ }^{6}$ In particular, we now have $A=1.017, \omega=0.2023$ and $\chi=3.7937$. Of course, other experiments can be considered, namely we can anchor all the scale parameters to their baseline values, letting the steady state values of growth and labour, along with the Frisch elasticity, to change consistently with different values of the intertemporal elasticity of substitution. See Table 4.
} 
substitution) are crucial in determining the sign of the relationship between volatility and growth. In particular, the above results seem to suggest that the relationship between volatility and growth is negative when the values of the parameters measuring risk aversion and intertemporal elasticity of substitution are both relatively high or relatively low. On the other hand, when one is high and the other is low, introducing uncertainty has a positive effect on growth.

\section{Conclusion}

We have built an endogenous growth model characterised by Epstein-Zin preferences. Epstein-Zin preferences are a class of recursive preferences that allow to disentangle the parameters measuring risk aversion and intertemporal elasticity of substitution. Our simulations confirm the intuition that the relationship between volatility and growth can be either positive or negative, depending on the parameters governing the curvature of the utility function, namely risk aversion and elasticity of intertemporal substitution. In particular, we have found out that when these parameters are both relatively high or relatively low the relationship between volatility and growth is negative, while otherwise is negative. This finding explains why employing traditional Von Neumann Morgenstern preferences misleadingly show that uncertainty always has a positive effect on growth: since they constrain risk aversion and intertemporal elasticity of substitution to be one the inverse of the other, they simply fail to capture those situations in which such relationship is negative. Moreover, we show that when employing reasonable parameters values (for models employing Epstein Zin preferences) the model yields a negative relationship between volatility and growth. Even if there is mixed empirical evidence regarding the effect of uncertainty on long-term growth, recent estimates seem to point in favour of a negative relationship, in line with our findings.

\section{References}

Aghion, P., Angeletos, G. M., Banerjee, A., and Manova, K. (2010). Volatility and growth: Credit constraints and the composition of investment. Journal of Monetary Economics, 57(3):246-265.

Aghion, P. and Banerjee, A. (2005). Volatility and Growth. Number 9780199248612 in OUP Catalogue. Oxford University Press. 
Annicchiarico, B. and Pelloni, A. (2014). Productivity growth and volatility: How important are wage and price rigidities? Oxford Economic Papers, 66(1):306-324.

Bansal, R. and Yaron, A. (2004). Risks for the long run: A potential resolution of asset pricing puzzles. The Journal of Finance, 59(4):1481-1509.

Blackburn, K. and Pelloni, A. (2004). On the relationship between growth and volatility. Economics Letters, 83(1):123-127.

Blackburn, K. and Pelloni, A. (2005). Growth, cycles, and stabilization policy. Oxford Economic Papers, 57(2):262-282.

Campanale, C., Castro, R., and Clementi, G. L. (2010). Asset pricing in a production economy with chew-dekel preferences. Review of Economic Dynamics, 13(2):379-402.

Campos, N. F. and Karanasos, M. G. (2008). Growth, volatility and political instability: Non-linear time-series evidence for Argentina, 1896 - 2000. Economics Letters, 100(1):135-137.

Canton, E. (2002). Business cycles in a two-sector model of endogenous growth. Economic Theory, 19(3):477-492.

Croce, M. M. et al. (2006). Welfare costs, long run consumption risk, and a production economy. In 2006 Meeting Papers, number 582. Society for Economic Dynamics.

De Hek, P. A. (1999). On endogenous growth under uncertainty. International Economic Review, 40(3):727-744.

Epaulard, A. and Pommeret, A. (2003). Recursive utility, endogenous growth, and the welfare cost of volatility. Review of Economic Dynamics, 6(3):672-684.

Epstein, L. G. and Zin, S. E. (1989). Substitution, risk aversion, and the temporal behavior of consumption and asset returns: A theoretical framework. Econometrica, 57(4):937-69.

Femminis, G. (2008). Risk-aversion and the investment-uncertainty relationship: The role of capital depreciation. Journal of Economic Behavior and Organization, 65(3-4):585-591.

Grier, K. B., Henry, l. T., Olekalns, N., and Shields, K. (2004). The asymmetric effects of uncertainty on inflation and output growth. Journal of Applied Econometrics, 19(5):551-565. 
Grier, K. B. and Perry, M. J. (2000). the Effects of Real and Nominal Uncertainty on Inflation and Output Growth : Some Garch-M Evidence. Journal of Applied Econometrics, 58(January 1999):45-58.

Jones, L. E., Manuelli, R. E., Siu, H. E., and Stacchetti, E. (2005). Fluctuations in convex models of endogenous growth, I: Growth effects. Review of Economic Dynamics, 8(4):780-804.

Judd, K. L. and Guu, S.-M. (1997). Asymptotic methods for aggregate growth models. Journal of Economic Dynamics and Control, 21(6):1025-1042.

Krebs, T. (2003). Growth and welfare effects of business cycles in economies with idiosyncratic human capital risk. Review of Economic Dynamics, 6(4):846-868.

Kreps, D. M. and Porteus, E. L. (1978). Temporal resolution of uncertainty and dynamic choice theory. Econometrica, 46(1):185-200.

Kung, H. and Schmid, L. (2015). Innovation, growth, and asset prices. The Journal of Finance, 70(3):1001-1037.

Loayza, N. and Hnatkovska, V. V. (2004). Volatility and growth. World Bank Policy Research Working Paper, (3184).

Martin, P. and Rogers, A. C. (2000). Long-term growth and short-term economic instability. European Economic Review, 44(2):359-381.

Mobarak, A. M. (2005). Democracy, volatility, and economic development. Review of Economics and Statistics, 87(2):348-361.

Rafferty, M. (2005). The effects of expected and unexpected volatility on long-run growth: evidence from 18 developed economies. Southern Economic Journal, pages 582-591.

Ramey, G. and Ramey, V. A. (1995). Cross-country evidence on the link between volatility and Ggrowth. American Economic Review, 85(5):1138-1151.

Saltari, E. and Ticchi, D. (2007). Risk aversion, intertemporal substitution, and the aggregate investment-uncertainty relationship. Journal of Monetary Economics, 54(3):622-648. 
Schmitt-Grohé, S. and Uribe, M. (2004). Solving dynamic general equilibrium models using a second-order approximation to the policy function. Journal of economic dynamics and control, $28(4): 755-775$.

Trabandt, M. and Uhlig, H. (2011). The Laffer curve revisited. Journal of Monetary Economics, $58(4): 305-327$.

Van Binsbergen, J. H., Fernández-Villaverde, J., Koijen, R. S. J., and Rubio-Ramírez, J. (2012). The term structure of interest rates in a DSGE model with recursive preferences. Journal of Monetary Economics, 59(7):634-648.

Wang, P.-F. and Wen, Y. (2011). Volatility, growth, and welfare. Journal of Economic Dynamics and Control, 35(10):1696-1709. 
Figure 1: Volatility and Growth in the U.S.
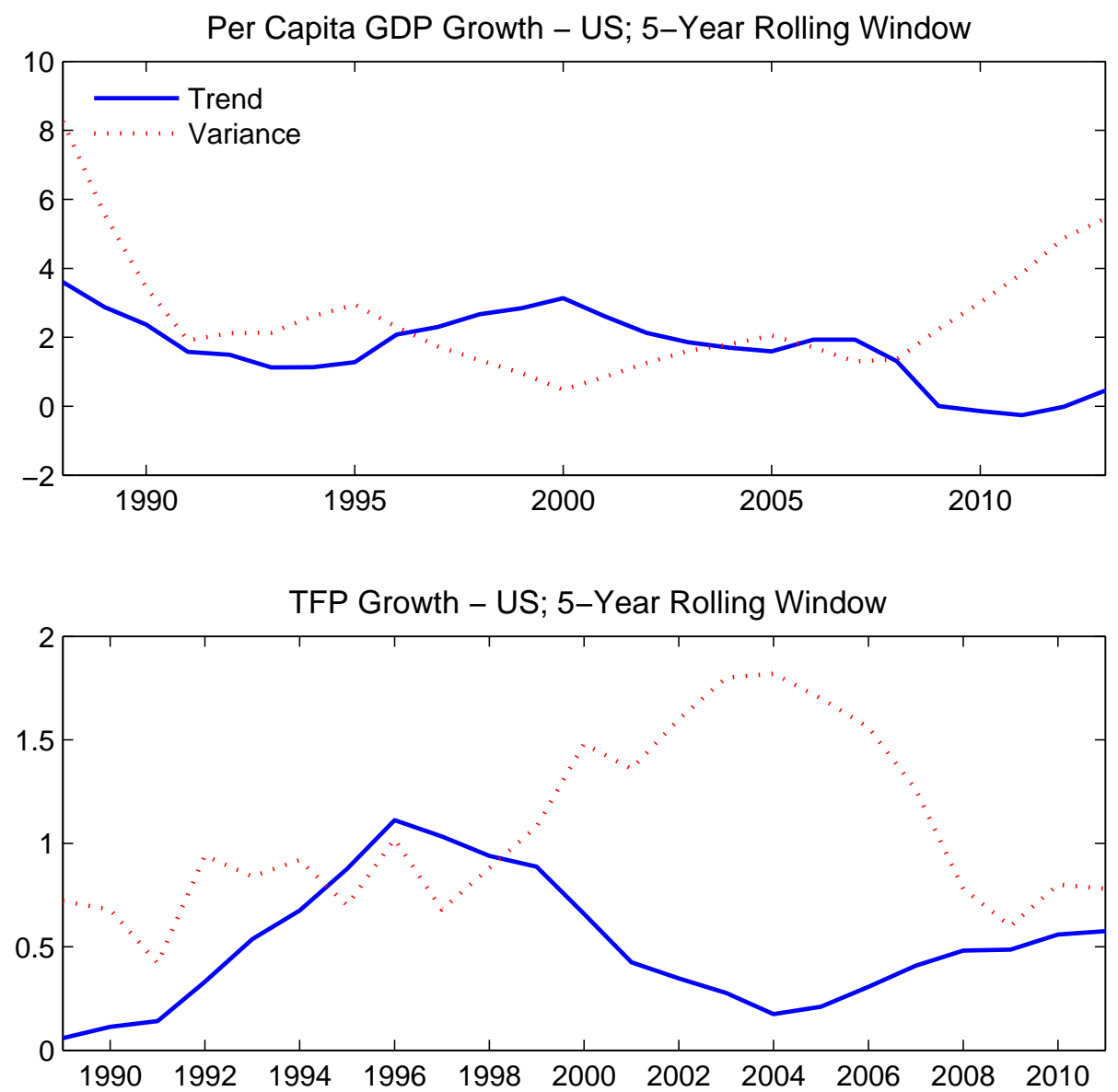

Source: Our elaborations on data from OECD - Compendium of Productivity Indicators and World Bank - World Development Indicators. 
Table 1: Benchmark calibration

\begin{tabular}{clc}
\hline \hline Fixed Parameters & \\
\hline$\beta$ & Discount factor & 0.95 \\
$\alpha$ & Share of capital & 0.36 \\
$\delta$ & Capital depreciation rate & 0.075 \\
$\sigma$ & Standard deviation of the shock & 0.011 \\
$\varphi$ & Persistence of the shock & 0.95 \\
$\gamma$ & Risk aversion & 10 \\
$\psi=\rho^{-1}$ & Intertemporal elasticity of substitution & 1.73 \\
\hline Implied & Parameters & \\
\hline$A$ & Technological constant & 0.84 \\
$\omega$ & Leisure-share & 0.0025 \\
$\chi$ & Leisure scaling parameter & 3.92 \\
\hline \hline
\end{tabular}


Table 2: Expected Output Growth and Risk Aversion $(\psi=1.73)$

\begin{tabular}{cccccc}
\hline \hline$\gamma$ & $E\left(g^{y}\right)$ & $E(n)$ & $\gamma$ & $E\left(g^{y}\right)$ & $E(n)$ \\
\hline 0.50 & 2.117 & 0.171 & 10.00 & 1.715 & 0.167 \\
1.00 & 2.092 & 0.171 & 12.00 & 1.647 & 0.167 \\
2.00 & 2.061 & 0.170 & 14.00 & 1.575 & 0.166 \\
4.00 & 1.961 & 0.169 & 16.00 & 1.476 & 0.165 \\
6.00 & 1.899 & 0.169 & 18.00 & 1.400 & 0.165 \\
8.00 & 1.810 & 0.168 & 20.00 & 1.323 & 0.164 \\
\hline \hline
\end{tabular}

Table 3: Expected Output Growth and Risk Aversion $(\psi=0.5)$

\begin{tabular}{cccrrr}
\hline \hline$\gamma$ & $E\left(g^{y}\right)$ & $E(n)$ & \multicolumn{1}{c}{$\gamma$} & $E\left(g^{y}\right)$ & $E(n)$ \\
\hline 0.30 & 1.998 & 0.170 & 8.00 & 2.055 & 0.170 \\
0.50 & 1.999 & 0.170 & 10.00 & 2.071 & 0.170 \\
1.00 & 2.007 & 0.170 & 12.00 & 2.080 & 0.171 \\
2.00 & 2.015 & 0.170 & 14.00 & 2.096 & 0.171 \\
3.00 & 2.022 & 0.170 & 16.00 & 2.111 & 0.171 \\
4.00 & 2.023 & 0.170 & 18.00 & 2.126 & 0.171 \\
6.00 & 2.037 & 0.170 & 20.00 & 2.141 & 0.171 \\
\hline \hline
\end{tabular}

Table 4: Expected Output Growth and the Intertemporal Elasticity of Substitution $(\gamma=10)$

\begin{tabular}{rrrrrrrrrr}
\hline \hline$\psi$ & $E\left(g^{y}\right)$ & $g^{y}$ & $E(n)$ & $n$ & $\psi$ & $E\left(g^{y}\right)$ & $g^{y}$ & $E(n)$ & $n$ \\
\hline 0.2 & 0.140 & 0.064 & 0.154 & 0.154 & 1.1 & 0.602 & 0.604 & 0.158 & 0.158 \\
0.3 & 0.171 & 0.100 & 0.154 & 0.154 & 1.2 & 0.688 & 0.718 & 0.159 & 0.159 \\
0.4 & 0.204 & 0.141 & 0.155 & 0.154 & 1.3 & 0.803 & 0.854 & 0.160 & 0.160 \\
0.5 & 0.245 & 0.185 & 0.155 & 0.155 & 1.4 & 0.941 & 1.020 & 0.161 & 0.162 \\
0.6 & 0.284 & 0.235 & 0.155 & 0.155 & 1.5 & 1.110 & 1.227 & 0.162 & 0.163 \\
0.7 & 0.337 & 0.291 & 0.156 & 0.156 & 1.6 & 1.328 & 1.497 & 0.164 & 0.166 \\
0.8 & 0.388 & 0.354 & 0.156 & 0.156 & 1.73 & 1.715 & 2.000 & 0.167 & 0.170 \\
0.9 & 0.444 & 0.426 & 0.157 & 0.157 & 1.8 & 2.035 & 2.395 & 0.170 & 0.173 \\
1 & 0.518 & 0.508 & 0.157 & 0.157 & 2 & 3.784 & 5.312 & 0.186 & 0.200 \\
\hline \hline
\end{tabular}




\section{Appendix}

\section{Unitary Intertemporal Elasticity of Substitution}

As mentioned before, in order to study the case in which the agent has unitary intertemporal elasticity of substitution, we first need to rewrite the individual's utility as follows

$$
U_{t}=\left[C_{t}\left(1-\chi n_{t}\right)^{1-\omega}\right]^{1-\beta}\left[E_{t}\left(U_{t+1}^{1-\gamma}\right)\right]^{\frac{\beta}{1-\gamma}}
$$

this result is obtained taking the limit of the utility function for $\psi$ approaching one and using l'Hôpital's rule. In this case, the stochastic discount factor is equal to:

$$
M_{t+1}=\beta \frac{C_{t}}{C_{t+1}} \frac{V_{t+1}^{1-\gamma}}{E_{t} V_{t+1}^{1-\gamma}} .
$$

Therefore, the set of stationarized equilibrium conditions when $\psi=1$ is now is given by

$$
V_{t}=\left[c_{t}\left(1-\chi n_{t}\right)^{1-\omega}\right]^{1-\beta}\left[E_{t}\left(V_{t+1}^{1-\gamma}\right)\right]^{\frac{\beta}{1-\gamma}}
$$

and by equations (15)-(18). Notice that, with this transformation, the utility function is still homogeneous of degree 1 . Moreover, $M_{t+1}$ is now equal to

$$
M_{t+1}=\beta\left[\frac{c_{t}}{g_{t+1} c_{t+1}} \frac{V_{t+1}^{1-\gamma}}{E_{t}\left(V_{t+1}^{1-\gamma}\right)}\right] .
$$

Finally, it is worth stressing that in this special case we will use the same simulation method and the same calibration that we employ for the general model.

\section{Unitary Risk Aversion}

As in the previous case, when risk aversion is equal to one we will need to find an alternative preferences representation. In particular, taking the limit of the original function for $\gamma$ approaching 1 and applying de L'Hopital's rule, we obtain:

$$
U_{t}=\left[(1-\beta)\left(C_{t}\left(1-\chi n_{t}\right)^{1-\omega}\right)^{1-\rho}+\beta E_{t}\left(U_{t+1}\right)^{1-\rho}\right]^{\frac{1}{1-\rho}} .
$$


Therefore, the set of stationarized equilibrium condition now is given by

$$
V_{t}=\left[(1-\beta)\left(c_{t}\left(1-\chi n_{t}\right)^{1-\omega}\right)^{1-\rho}+\beta g_{t+1}^{1-\rho} E_{t}\left(V_{t+1}\right)^{1-\rho}\right]^{\frac{1}{1-\rho}} .
$$

and by equations (15)-(18). In this case the stochastic discount factor in stationary variables is

$$
M_{t+1}=\beta\left(\frac{V_{t+1}}{E_{t}\left(V_{t+1}\right)} \frac{c_{t}}{g_{t+1} c_{t+1}}\right)^{\rho}\left(\frac{\left(1-\chi n_{t+1}\right)^{1-\omega}}{\left(1-\chi n_{t}\right)^{1-\omega}}\right)^{1-\rho} .
$$

The calibration and simulation method remains the same also in this case.

\section{Frisch Elasticity}

Given the specification of preferences in (6), we calculate the elasticity of labour supply with respect to the real wage, keeping utility constant

$$
\text { Frisch }=\left.\frac{d n_{t}}{d w_{t}} \frac{w_{t}}{n_{t}}\right|_{\lambda_{t}}
$$

where $\lambda_{t}$ is the multiplier associated with the constraint (8).

We start from the following two necessary conditions for an optimum:

$$
\begin{gathered}
V_{t}^{\rho}(1-\beta) C_{t}^{-\rho}\left(\left(1-\chi n_{t}\right)^{1-\omega}\right)^{1-\rho}=\lambda_{t}, \\
(1-\omega) \chi V_{t}^{\rho}(1-\beta) C_{t}^{1-\rho}\left(1-\chi n_{t}\right)^{(1-\omega)(1-\rho)-1}=\lambda_{t} w_{t} .
\end{gathered}
$$

From (A-8) we can find the following representation of $C_{t}$ :

$$
C_{t}=\left[\frac{(1-\beta)\left(\left(1-\chi n_{t}\right)^{1-\omega}\right)^{1-\rho}}{\lambda_{t}}\right]^{\frac{1}{\rho}} V_{t}
$$

Plugging this result in (A-9), we have:

$$
(1-\omega) \chi V_{t}(1-\beta)^{\frac{1}{\rho}}\left(1-\chi n_{t}\right)^{\frac{(1-\omega)(1-\rho)-\rho}{\rho}}=w_{t} \lambda_{t}^{\frac{1}{\rho}}
$$


or

$$
n_{t}=\chi^{-1}\left[1-\left(\frac{\lambda_{t}^{\frac{1}{\rho}} w_{t}}{(1-\omega) \chi V_{t}} \frac{1}{(1-\beta)^{\frac{1}{\rho}}}\right)^{\frac{\rho}{(1-\omega)(1-\rho)-\rho}}\right]
$$

from which it is straightforward to compute the derivative:

$$
\frac{\partial n_{t}}{\partial w_{t}}=-\frac{1}{\chi} \frac{\rho}{(1-\omega)(1-\rho)-\rho}\left(\frac{\lambda_{t}^{\frac{1}{\rho}}}{(1-\omega) \chi V_{t}} \frac{1}{(1-\beta)^{\frac{1}{\rho}}}\right)^{\frac{\rho}{(1-\omega)(1-\rho)-\rho}} w_{t}^{\frac{\rho}{(1-\omega)(1-\rho)-\rho}-1} .
$$

Plugging (A-12) and (A-13) in (A-7) and simplifying we have:

$$
\text { Frisch }=\frac{1}{\chi} \frac{\rho}{\rho-(1-\omega)(1-\rho)} \frac{1-\chi n_{t}}{n_{t}} .
$$

